\title{
A economia política da financeirização: possíveis implicações no mundo do trabalho
}

\author{
The political economy of financialization: possible implications for labor
}

\author{
Vinícius Ferreira Lins'
}

\begin{abstract}
Resumo
A financeirização envolve a predominância dos mercados e demais instituições financeiras como a forma de definição, gestão e realização da riqueza no capitalismo contemporâneo. O processo de financeirização da economia foi possível a partir de um processo subjacente de flexibilização, que se manifestou em uma nova forma de regulação bem como no advento de novos instrumentos financeiros, notadamente securitização e derivativos. Isto ensejou um aumento inaudito no grau de liberdade, no volume e na complexidade do movimento de capitais, trazendo a competição a outro patamar. Isto acarretou mudanças tanto na forma de governança da firma quanto nas relações de trabalho. Este artigo tem por objetivo identificar e explorar possíveis relações causais entre as transformações nas finanças e as alterações nas condições de vida e de trabalho. A flexibilidade nos mercados financeiros e de crédito, embora não deva ser considerada causa única, teve parte significativa no advento da flexibilidade no trabalho. As distintas considerações aqui discutidas, embora sob perspectivas diferentes, apontam para uma deterioração das condições de venda da mercadoria força de trabalho a partir da competitividade intensificada para a valorização do capital na esfera financeira.
\end{abstract}

Palavras-chave: Financeirização; Flexibilização; Trabalho

\begin{abstract}
Financialization involves the predominance of markets and other financial institutions as the form of definition, management and realization of wealth in contemporary capitalism. The process of financialization of the economy was made possible by an underlying process of flexibility, which manifested itself in a new form of regulation as well as in the advent of new financial instruments, notably securitization and derivatives. This led to an unprecedented increase in the degree of freedom, volume and complexity of the capital movement, bringing competition to another level. This has led to changes in both the firm's governance and labor relations. This article aims to identify and explore possible causal relationships between changes in finances and changes in living and working conditions. Flexibility in the financial and credit markets, although it should not be considered as a single cause, played a significant part in the advent of flexibility at work. The different considerations discussed here, albeit under different perspectives, point to a deterioration in the conditions of sale of the commodity "labor force" due to the intensified competitiveness to the valorization of capital in the financial sphere.
\end{abstract}

Keywords: Financialization; Flexibility; Labor

${ }^{I}$ Mestre em Economia pela Universidade Federal da Bahia e Doutorando em Desenvolvimento Econômino pela Universidade Federal da Bahia, lins.vinicius@live.com 


\section{Introdução}

A financeirização é um tema que ganha progressiva importância na última década. Como todo legítimo debate nas Ciências Humanas, apresenta múltiplas facetas e ausência de consenso. As transformações que vêm acontecendo no mundo do trabalho, consubstanciadas na chamada Reforma Trabalhista ou em alterações esparsas e pontuais, não estão, evidentemente, dissociadas do que acontece nas praças financeiras. O crescente endividamento das famílias, sobretudo em razão do acesso às necessidades mais básicas como saúde, educação e previdência, bem como a precarização dos postos de trabalho coexiste com uma pujança inaudita da finança, que se patenteia indisfarçavelmente nas comparações do tipo "riqueza financeira x riqueza real".

Este artigo tem por objetivo identificar e explorar possíveis relações causais entre as transformações nas finanças e as alterações nas condições de vida e de trabalho. Aqui não se busca explicar a complexa dinâmica do mundo do trabalho, que se manifesta de formas distintas nos seus respectivos contextos, como decorrência linear do processo de financeirização da economia global. Este também, apesar de ubíquo, apresenta múltiplas características que, a depender do contexto, fazem-se mais ou menos presentes. Tão somente procura-se perscrutar possíveis relações mais ou menos diretas.

O artigo está organizado em duas partes. Na primeira, após uma breve revisão de literatura sobre o conceito de financeirização, busca-se elaborar uma descrição analítica dos elementos que culminaram com a predominância da finança, notadamente a regulamentação específica de cariz neoliberal (que amiúde aparece sob a terminologia não-neutra de "desregulamentação").

$\mathrm{Na}$ segunda parte, articula-se o que foi discutido anteriormente sob o argumento de que a flexibilidade que passa a caracterizar a acumulação de capital sob a forma financeira traz consigo não apenas a flexibilização do mercado de trabalho como per se como uma deterioração nas próprias condições de trabalho.

Em seguida, as considerações finais fecham o trabalho.

\section{A economia política da financeirização}

Epstein (2001, p.1) entende que "financeirização" se refere à "importância crescente dos mercados financeiros, motivos financeiros, instituições financeiras, e as elites financeiras nas operações da economia e instituições que a governam, seja a nível nacional ou internacional”. Na mesma direção, Krippner (2005, p.174) define como “um padrão de acumulação no qual os lucros advêm primariamente de canais financeiros ao invés do comércio e produção de mercadorias. Palley (2007, p.2), por sua vez, considera a financeirização como "um processo pelo qual os mercados financeiros, instituições financeiras e as elites financeiras ganham maior influência sobre a política econômica e os resultados econômicos”. Já para Braga (2013), a financeirização é um padrão sistêmico de definição (pelo tripé moeda-crédito-patrimônio), gestão (pela macroestrutura financeira) e realização da riqueza (dinheiro e ativos financeiros predominantes sobre os operacionais) em um número crescente de países.

Van der Zwan (2014, p.101), por seu turno, considera que a financeirização refere-se a "uma teia de processos inter-relacionados - econômicos, políticos, sociais, tecnológicos, culturais etc. - pelos quais as finanças estenderam sua influência para além do mercado e para outros domínios da vida social". Trata-se, assim, de um processo que "abrange uma série de fenômenos empíricos em diferentes níveis de análise" (VAN DER ZWAN, 2014, p.101). Uma visão completa desse processo perpassa pelo menos por três abordagens distintas. Uma primeira entende a financeirização como um regime de acumulação conduzido pela finança (finance-led) que se coloca como sucessor do regime de acumulação fordista. A segunda abordagem identifica a financeirização com a emergência da maximização do valor para o acionista como o princípio orientador da governança corporativa moderna. Por fim, uma terceira abordagem associa a financeirização com a maneira pela qual a finança vem ocupando um crescente espaço nas práticas da vida cotidiana, notadamente como canal de provisão monetária para necessidades básicas.

Outro modo de ver a financeirização poder ser como o processo subjacente ao que Wolfgang Streeck denomina de transformação do Estado de Dívida em Estado de Consolidação, que seria aquele regido pelo compromisso político de, a qualquer custo, garantir a manutenção de fluxo de rendas para os credores (STREECK, 2016).

De toda sorte, a financeirização é um processo diretamente atrelado às transformações na economia global sobretudo nas décadas de 1970 e 1980. Para compreendê-las, faz-se necessário analisar como estava organizado o mundo das finanças no período imediatamente anterior.

De acordo com Braga e Cintra (2004), após da débâcle de 1929, foi necessário que os EUA reorganizassem toda a estrutura financeira. A reconstrução institucional se deu pelo Glass-Steagall Act de 1933 (Banking Act), que proibia a posse de ações pelos bancos e restringia a 15\% o máximo de seu capital que poderia ser alocado em um cliente específico e pelo Securities Exchange Act de 1934, que estabeleceu a Securities and Exchange Commission, agência responsável pela aplicação da lei federal de valores mobiliários dos EUA. Essa lei, na prática, provia a regulamentação 
do mercado secundário, a fim de evitar práticas desiguais e injustas nas bolsas de valores e mercados de balcão operando no comércio interestadual e no comércio exterior. Assim, entre as décadas de 1930 e 1980 o sistema financeiro americano pode ser caracterizado como segmentado, regulamentado e regionalizado (BRAGA E CINTRA, 2004):

- Segmentado porque havia limite de atuação e escopo para os bancos, isto é, bancos comerciais apenas poderiam fazer transações com títulos e empréstimos para empresas e famílias. Não era permitido ter ações sem eu balanço, sendo que as transações com ações, por exemplo, ficavam a cargo dos bancos de investimento;

- Regulamentado com três características basilares: 1. Proteção estatal (sistema de seguro dos depósitos e mecanismos de supervisão); 2. Restrição à competição exacerbada entre as instituições financeiras (existia um teto para a taxa de juros, tanto na captação quanto no empréstimo) e 3. Intenção de transparência na gestão dos negócios;

- Regionalizado devido à existência de restrições à expansão das redes bancárias interestaduais (McFadden Act de 1927)

Sob o prisma do comércio internacional, o Acordo de Bretton Woods (1944) estabelecia, inter alia, o câmbio fixo (admitindo variações de até 10\%), o ouro como ativo de referência, sendo obrigatória para uma moeda internacional a garantia da conversibilidade automática no metal, o que limitaria a expansão exacerbada da liquidez. Dessa forma, as moedas nacionais seriam livremente conversíveis umas nas outras. Sucede que, na prática, o sistema não era neutro e favoreceu enormemente os EUA porque partiu de uma situação profundamente assimétrica. Os EUA, no imediato pós-guerra, detinham dois terços das reservas mundiais de ouro. Logo, a única moeda que, de fato, poderia garantir uma livre conversibilidade em ouro era o dólar americano, o que levou à aceitação em escala planetária dessa moeda como meio de pagamento, unidade de conta e reserva de valor. Assim, o arcabouço institucional caracterizava um sistema estável com mecanismos que limitavam a liberdade das instituições financeiras de correrem riscos, bem como controlavam sua rentabilidade. A liquidez das instituições financeiras, o baixo endividamento privado aliado ao seguro de depósitos promoviam a manutenção de uma baixa taxa de juros (BRAGA E CINTRA, 2004).

Do ponto de vista da governança da firma, o padrão vigente até meados da década de 70 baseou-se na estratégia de reter e reinvestir (LAZONICK e O'SULLIVAN, 2000). Uma vez que nesse período o capital industrial era o cerne da acumulação, a competição era baseada sobretudo na busca pela ampliação da fatia do mercado de produtos e serviços. O objetivo, então, era a dominância do mercado consumidor através de intenso processo de inovação baseados em vultosos dispêndios em P\&D. Havia uma separação entre a propriedade de ações e o controle gerencial, de forma que os gerentes de alto escalão estavam completamente integrados às empresas que os empregavam. $\mathrm{O}$ salário dos altos executivos era, pois, amplamente determinado pelas estruturas de remuneração dentro da organização gerencial (LAZONICK e O’SULLIVAN, 2000).

Assim, o modelo de governança vigente consistia em reter a maior parte possível dos lucros e reinvestir na própria empresa, isto é, na sua estrutura e organização bem como na capacitação dos seus executivos, gerentes e funcionários. Compunha-se assim um ambiente corporativo robusto e competitivo na conquista de fatias de mercado:

O fato é que, dado o domínio que essas corporações exerceram sobre muitos dos seus mercados de produtos, a busca de estratégias de retenção e reinvestimento permitiu um ganho a muitos grupos de interesse diferentes. Os trabalhadores podiam receber salários mais altos e ter melhores condições de trabalho e estabilidade no emprego; fornecedores e distribuidores podiam obter mais lucros, alguns dos quais poderiam ser repassados aos trabalhadores; os consumidores poderiam encontrar preços mais baixos nos produtos que compraram; os dividendos aos acionistas poderiam ser mantidos ou até aumentados; e ainda podia haver fundos substanciais para a corporação reinvestir nos Estados Unidos ou, como era cada vez mais frequente nessas décadas, no exterior (LAZONICK e O’SULLIVAN, 2000, p.25)

Sucede que a condição de dominância criaria, paradoxalmente, um impasse para os EUA. Para que o dólar cumprisse a função de moeda internacional e satisfizesse a crescente demanda por liquidez, em um contexto de reconstrução da Europa e da Ásia, seria necessário, na prática, a extinção do padrão-ouro e que os EUA incorressem em déficit no balanço de pagamentos. Aumentou-se o endividamento privado e a desvalorização dos títulos públicos, de forma a desembocar no aumento da inflação e da taxa de juros. Em um cenário de controle de taxas de juros (havia um teto para as instituições de depósito), as instituições de depósito buscariam maiores retornos no mercado monetário (inovações financeiras, quase-moedas), desembocando na desintermediação financeira e na preponderância dos investidores institucionais (BRAGA e CINTRA, 2004). É nesse sentido que Helleiner (1990) argumenta que, embora a situação acima descrita tenha parecido indicar a erosão da hegemonia financeira do país, o poder financeiro dos EUA não declinou, de fato, em relação a outros Estados, mas apenas vis-à-vis aos crescentes mercados financeiros globais. Além disso, a posição global do dólar não foi seriamente desafiada por desenvolvimentos como a criação do Sistema Monetário Europeu porque os mercados financeiros dos EUA ainda eram os mais atraentes para os investidores. 
A partir de meados da década de 1970, Chesnais (2005) vai identificar uma transformação no capitalismo que denomina "mundialização financeira". O autor evoca três elementos constitutivos da era da mundialização financeira - os

três “D” - que estão intimamente relacionados: desregulamentação', descompartimentalização e desintermediação:

- Desregulamentação - As medidas e leis envolvem a liberalização dos mercados de câmbio e capitais e acontece sucessivamente de maneira ad hoc, chancelando legalmente o que já ocorre na prática (BRAGA E CINTRA, 2004). Algumas das leis mais importantes nesse âmbito foram Depository Institutions Deregulation and Monetary Control Act (1980), que eliminou os tetos sobre as taxas de juros bem como permitiu a fusão entre bancos. O Garn-St Germain Depository Institutions Act (1982) desregulou as associações de poupança e empréstimo e permitiu que os bancos fornecessem empréstimos hipotecários com taxa ajustável. O Riegle-Neal Interstate banking and branching efficiency act (1994) permitiu a formação de bancos interestaduais (coast to coast branch banking). O Gramm-Leach-Bliley Act ou Finantial Modernisation Act (1999) - possibilitando a existência de bancos universais (holdings financeiras). Vale lembrar que em 1998 o Citibank havia comprado o Travelers Group (banco de investimento e seguradora, trazendo para dentro do grupo o que havia sido proibido pela lei de 1933);

- Descompartimentalização - Refere-se à uma flexibilização no escopo de atuação dos bancos. Pode ser de dois tipos, a descompartimentalização interna diz respeito ao fato de os bancos passarem a exercer diferentes funções financeiras e atuarem em diferentes mercados. A descompartimentalização externa remete à integração global dos mercados nacionais de câmbio, títulos e ações - (CHESNAIS, 2005);

- Desintermediação - Processo pelo qual instituições financeiras não bancárias - fundos mútuos, companhias de seguro, fundos de pensão - os chamados investidores institucionais - passarem a ter acesso aos mercados como emprestadores, oferecendo retornos mais atrativos às famílias e empresas, provocando assim uma "fuga dos bancos".

Portanto, em meio à instigada concorrência bancária, passou-se a intensificar os processos de fusões e aquisições bancárias, em um contexto de progressiva flexibilização legislativa das restrições e controles (geográficos e operacionais). Surgiram as holdings e o mercado bancário passa a não mais ser segmentado. São sobretudo esses investidores institucionais que vão centralizar poupanças e lucros não reinvestidos, inserindo-os no circuito de valorização dos mercados de divisas, obrigações e ações por meio de uma série de inovações financeiras, como securitização e derivativos. A securitização diz respeito à agregação de passivos financeiros de diferentes naturezas, os quais, consubstanciados em um novo produto financeiro, são negociados no mercado de capitais. Já os derivativos são contratos para pagamentos futuros cujo montante está associado à variação na cotação de determinados ativos subjacentes.

Tudo isso acima descrito caracteriza a "era da acumulação financeira” (CHESNAIS, 2005). Essa era pode ser caracterizada em três etapas. A primeira está associada ao surgimento dos mercados offshore. Ainda em 1957, em Londres, após um ataque contra a libra, governo impede transações em libras com não residentes - bancos ingleses decidem então transacionar em dólar - nasce o primeiro mercado offshore, ao que se seguem outros (Hong Kong, Singapura, Ilhas Cayman, Panamá etc.). Esses mercados crescem exponencialmente, passando a demandar uma quantidade cada vez maior de dólares, que passam a circular mundialmente fora da supervisão do Federal Reserve.

Em agosto de 1971, o presidente americano Richard Nixon suspende a conversibilidade do dólar em ouro - era o fim do Acordo de Bretton-Woods, consolidando a imposição da ordem americana ao resto do mundo pelo dólar sem nenhum lastro. Em outubro de 1979, Paul Volcker, presidente do Federal Reserve, aumenta as taxas de juros americanas de um patamar de $8 \%-10 \%$ para $22 \%$. Com isso, os dólares que estavam dispersos no mundo nesses mercados offshore voltam aos Estados Unidos em virtude da atratividade de valorização ensejada por esse aumento nas taxas de juros. O dólar consolida-se como moeda internacional. Segue-se que a queda na rentabilidade no investimento produtivo teria sido compensada pelos procedimentos de mark-up, o que, por um lado, conduziu a uma alta dos lucros, mas, por outro, repercutiu como alta geral nos preços e nos salários, bem como na quota de depreciação da margem bruta de reinvestimento (LIPIETZ, 1984). Sucedeu-se um comprometimento da capacidade de investir das empresas, dada a tendência de endividamento crescente, bem como aumento dos gastos financeiros, da depreciação e do preço relativo dos investimentos, tudo isso em um ambiente inflacionário. A partir de 1982, tem-se a globalização financeira, que em última instância é nada mais do que a expansão da forma de gestão da riqueza americana para o mundo.

\footnotetext{
1 Embora seja o termo consagrado na literatura, na realidade, trata-se antes de uma nova regulamentação do que, de fato, desregulamentação. O termo "desregulamentação" parece dar a ideia (de conotação positiva) de que se promove um desembaraço, uma convergência a um estado natural, puro e imparcial. A ausência de limites ou requisitos para a ação das instituições financeiras, por exemplo, é em si uma regulamentação específica que, além de exigir um Estado forte que a garanta, está longe de ser imparcial.
} 
A segunda etapa remete à reciclagem dos petrodólares que, via empréstimos em condições desvantajosas, inseriu os países da periferia na ciranda financeira. A terceira etapa diz respeito à transformação dos dividendos em um importante mecanismo de acumulação via "governo de empresa", pelo qual os investidores institucionais, agora donos de empresas e credores de governos, ditam "novas normas de rentabilidade que geram pressões bastante acentuadas sobre salários, tanto em termos de produtividade e flexibilidade do trabalho quanto, como de mudanças nas formas de determinação dos salários” (CHESNAIS, 2005, p.42), influenciando, assim, na distribuição da riqueza entre salários, lucros e renda financeira e sua repartição entre "investimentos produtivos", juros e dividendos.

Em termos gerais, o padrão de gestão da riqueza vai promover a realização simultânea de lucros operacionais e financeiros, com predominância desses últimos. Essa é uma das principais características da financeirização. A configuração do capitalismo passa assim a ser caracterizada por a) um mercado de capitais conexos com o sistema creditício; b) desenvolvimento do capital financeiro como com variadas formas de combinação do lucro operacional e lucro financeiro; c) avançado estágio da centralização do capital; uso da taxa básica de juros de curto prazo americana (federal funds rate) como regulador do movimento de capitais globalmente; padrão instável de gestão da riqueza; ubiquidade das práticas das instituições multilaterais e definição das regras por essas instituições (BRAGA E CINTRA, 2004). Isso está diretamente relacionado à nova estratégia de governança das empresas.

Lazonick e O'Sullivan (2000) explicam que em virtude das transformações acima descritas, tornou-se difícil para os altos executivos encontrar novas formas de gerar ganhos de produtividade com base na estratégia de "reter e reinvestir", passando à estratégia de "reduzir e distribuir", cujo cerne está no princípio de "maximização do valor ao acionista". A teoria que dá suporte a esse princípio diz que o controle via mercado é mais eficiente do que o controle dos gerentes corporativos no que tange à alocação de recursos e retornos. Com a nova regulação vigente no ambiente financeiro, os investidores institucionais figuram como maiores detentores de ações corporativas e supostamente têm maior acesso e capacidade de processamento de informações relevantes do que os gerentes corporativos. Tendem, assim, via distribuição de fluxos de caixa, a alocar os recursos de forma mais eficiente, o que vai ser sinalizado na valorização/desvalorização das ações e, por conseguinte, das próprias empresas. Logo, a performance geral de uma empresa fica diretamente relacionada ao seu desempenho no mercado acionário.

Desde os anos 1950, opções de ações (stock options) já vinham compondo parte da remuneração dos altos executivos, principalmente devido a vantagens fiscais. No entanto, é só no final dos anos 1970 que isso vai se materializar em uma mudança na estrutura de governança da firma e em uma crescente diferença no montante da remuneração entre os altos executivos e demais trabalhadores:

Durante as décadas de 1950 e 1960, com o mercado de ações em geral em alta, os ganhos com o exercício dessas opções e a manutenção de ações tornaram-se componentes cada vez mais importantes dos rendimentos dos altos executivos. Quando, no início dos anos 1970, o mercado de ações sofreu uma baixa, muitos conselhos corporativos transformaram opções sem valor em ações em aumentos na remuneração assalariada, sob o argumento de que esses gerentes não podiam ser culpados pela crise geral no mercado de ações. Com efeito, as expectativas de ganhos das opções de ações que haviam sido formadas durante o aumento geral do mercado de ações nas décadas de 1950 e 1960 passaram a ser consideradas, juntamente com os salários, como parte da remuneração básica dos altos executivos. Assim começou uma tendência que durante a década de 1970 favoreceu o pagamento dos gestores de topo sobre o pagamento de todos os outros na corporação (LAZONICK e O’SULLIVAN, 2000, p.24-25)

Com um interesse pessoal crescente no aumento do valor de mercado das ações da empresa que dirigiam, os altos executivos passaram então a alinhar a seus próprios objetivos com interesses financeiros externos em detrimento dos interesses das firmas que dirigiam. Dessa forma, com a cumplicidade dos principais gerentes corporativos, "a maximização do valor para o acionista" torna-se então o padrão de princípio de governança corporativa dos EUA (LAZONICK e O'SULLIVAN, 2000). Na prática, os gerentes de alto escalão passam a executar uma redução na quantidade de trabalhadores e na própria estrutura física da empresa na tentativa de aumentar o retorno sobre o patrimônio líquido.

Chesnais $(2005$, p.55) considera que são os trabalhadores assalariados o grupo social sobre o qual recaem majoritariamente os impactos proprietários-acionistas: "é contra eles que se exerce o novo poder administrativo. Foram eles que sofreram e vão continuar a sofrer (...) os efeitos das normas de rentabilidade impostas pelos financistas". Ele detalha ainda que o movimento de altas taxas de rendimento conjugadas a um crescimento nos lucros só foi possível em virtude do "rigor salarial e a flexibilização do emprego, assim como o recurso sistemático ao trabalho barato e pouco protegido por meio da deslocalização e subcontratação internacional" (CHESNAIS, 2005, p.55). Os "administradores financeiros" também se concentraram na distribuição de receitas corporativas na forma de dividendos e recompra de ações - que se consolida de forma sistemática como um destino cada vez mais importante na alocação das receitas - a fim de a sustentar o preço das ações de suas empresas no mercado (LAZONICK e O’SULLIVAN, 2000). 
Todo esse processo de liberalização não ocorreu apenas por razões econômicas, mas sobretudo políticas. Helleiner (1994) argumenta que esse processo decorreu também dos interesses especiais hegemônicos dos três estados que abrigavam os principais centros financeiros dos anos 1980 (Estados Unidos, Inglaterra e Japão) - cujo apoio ao liberalismo financeiro refletiam em parte suas respectivas posições como poderes financeiros respectivamente existente, decadente e emergente. Quando um Estado começou a desregulamentar e liberalizar seus mercados financeiros, outros Estados foram forçados a seguir sua liderança a fim de permanecerem competitivos na atração de fundos e negócios financeiros.

A mudança de políticas baseadas em estruturas de pensamento reformista (keynesiano/social democrata) para neoliberal consolidou a crescente força de uma coalizão de interesses financeiros privados, empresas industriais multinacionais e autoridades financeiras que apoiavam a abertura financeira. Fica claro, de todo modo, que o processo de liberalização foi regulamentado. Isto é, não aparece como um desdobramento natural (evolução) dentro da economia, mas como projeto de poder (HELLEINER, 1994).

O período em tela coincide com o que Streeck (2016) identifica como a passagem do Estado de Dívida (Debt State) para Estado de Consolidação (Consolidation State). A partir de meados dos anos 1970, a dívida acumulada dos Estados membros da OCDE começa a aumentar progresivamente. Essa progressão acentuada e constante do gasto público coincidiu com um declínio geral e acentuado do poder político do trabalho organizado (GRÁFICOS $1 \mathrm{e}$ 2). Os governos foram instilados, assim, a substituir os impostos (cuja coleta ensejava altos custos políticos) pelo crédito como fonte de recursos. À medida que a oferta de crédito geral se expandia, não eram apenas os Estados que se tornavam cada vez mais "alavancados", mas também as empresas e, mais adiante, as famílias.

Gráfico 1 - Taxa de sindicalização - Razão entre assalariados membros de sindicatos e assalariados totais (\%) Países da OCDE ${ }^{2}$

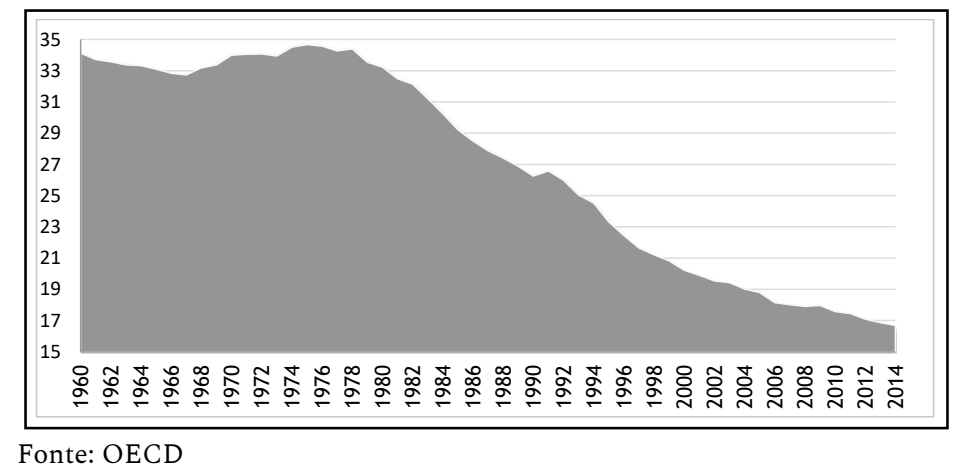

Houve uma diminuição na razão entre assalariados sindicalizados e o total, que havia chegado a 34,7\% em 1975, mantendo-se em queda livre, ficando abaixo dos 16,7\% em 2014, como mostrado no Gráfico 1.

Gráfico 2 - Taxa de cobertura de negociação coletiva (\%) - Países da OCDE

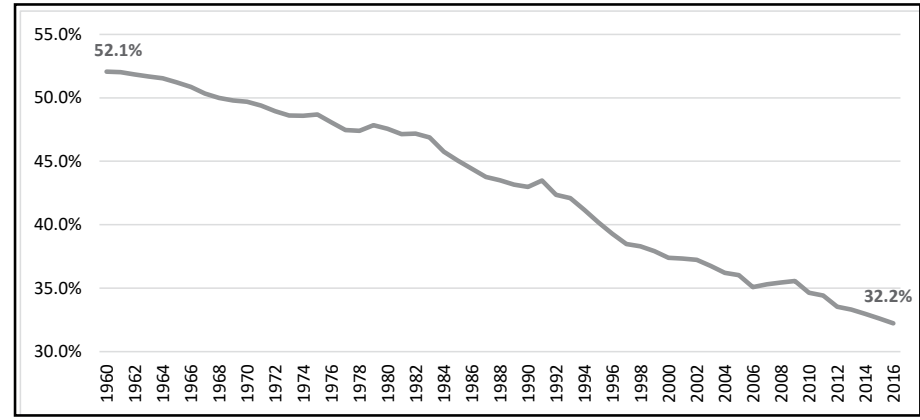

Fonte: OECD

2 Países da OCDE, desde 1948: Áustria, Bélgica, Dinamarca, França, Grécia, Holanda, Islândia, Irlanda, Itália, Luxemburgo, Noruega, Portugal, Reino Unido, Suécia, Suíça, Turquia. Admitidos posteriormente: Alemanha (1955), Espanha (1959), Canadá (1961), Estados Unidos (1961), Japão (1964), Finlândia (1969), Austrália (1971), Nova Zelândia (1973), México (1994), República Checa (1995), Hungria (1996), Polônia (1996), Coréia do Sul (1996), Eslováquia (2000), Chile (2010), Eslovênia (2010), Estônia (2010), Israel (2010), Letônia (2016). 
A taxa de cobertura da negociação coletiva corresponde (proporção de empregados abrangidos por acordos coletivos) viria a consolidar uma tendência de queda em meados dos anos 80, fechando 2016 com o nível mais baixo da série histórica $(32,2 \%)$.

Streeck (2016) explica que um Estado de Consolidação (Consolidation State) estabelecido é aquele que logrou institucionalizar, via compromisso político, a colocação de suas obrigações para com seus credores acima de todas as outras obrigações. Sua característica é apresentar uma configuração geral de forças políticas que promovem cortes nos gastos em todas as searas exceto no serviço da dívida. Além de garantir aos credores um fluxo de renda vultoso, o estabelecimento de um Estado de Consolidação enseja também uma oportunidade para "reduzir" o Estado em favor do setor privado, promovendo assim a substituição de serviços públicos, outrora gratuitos, pelo crédito. Assim, à medida que as famílias se endividam para compensar os cortes na provisão pública, concomitantemente o setor privado passa a ocupar áreas que antes eram do domínio do governo. "Onde há menos bens públicos devido à privatização, há menos para se decidir politicamente e a democracia econômica do capitalismo - um dólar, um voto - começa a substituir a democracia política” (STREECK, 2016, p.140).

Trata-se de um arranjo mais que "virtuoso" para, sobretudo, os setores ligados às finanças e serviços de educação e saúde privados, enquanto que reflete na deterioração das condições de vida dos cidadãos. Isso pode ser ilustrado pelo fato de uma mulher gravemente ferida em um acidente no metrô, nos Estados Unidos, implorar para que não chamassem uma ambulância porque não teria como pagar. O custo médio do serviço varia entre US\$1.200,00 e US\$ 1.900 (CRAMER e COATE, 2018). The New York Times, em editorial, lamentou o estado da Saúde no país, pontuando a "despesa potencialmente monumental de serviços básicos, com curativos ou transporte para o hospital" e o fato de gastarem 17\% do PIB com Saúde "não porque os americanos usam mais serviços médicos - é porque os cuidados de saúde são muito mais caros aqui do que em outros países" (THE EDITORIAL BOARD, 2018, p1). Outro fato preocupante é o endividamento dos universitários, que supera US\$1,5 trilhão- maior que o PIB da Espanha. A dívida média do recém-formado chega a US\$28.400, sendo ainda maior para os que vão para universidades privadas (POZZI, 2018).

De acordo com Streeck (2016), a crise de 2008 evidenciou cabalmente a estreita interligação entre o Estado de dívida (debt state) e a financeirização, uma vez que os Estados foram coagidos a absorver a dívida incobrável criada pelo setor privado sob a regulamentação financeira neoliberal. Essa estatização da dívida privada (para supostamente proteger as sociedades das consequências dos empréstimos especulativos) foi exatamente o que acabou por tornar os mercados financeiros receosos sobre a capacidade dos Estados de cumprir suas obrigações como devedores.

Streeck (2016) vislumbra quatro consequências político-econômicas nos Estados que se engajam na consolidação fiscal:

- À medida que os orçamentos públicos se aproximam de um equilíbrio, uma parcela crescente dos gastos do governo cobrirá despesas comparativamente rígidas e legalmente fixas, como despesa com pessoal e serviço da dívida. Terá lugar então a diminuição dos gastos discricionários e pressão para diminuição de volume e escopo de políticas sociais;

- Em decorrência, o investimento público encolherá. Demandas nas infraestruturas físicas e sociais devem ser atendidas pelos investidores privados, assumindo responsabilidades anteriormente públicas. Um dos prováveis efeitos é o largo uso de parcerias público-privadas (PPPs) de vários tipos, com investimento privado apoiado pelo público, e governos ou cidadãos individuais pagando taxas de uso para empresas privadas;

- O encolhimento dos gastos discricionários inevitavelmente envolve cortes nos serviços sociais como a educação e, especialmente, nos serviços universais que beneficiam a todos os cidadãos. Os mais abastados ficarão habituados a provisões mais personalizadas (e caras), o que fará com que exijam (mais) cortes de impostos, os quais impulsionarão mais cortes de gastos, dando seguimento à espiral de fragilização financeira do Estado.

- A privatização do investimento em infraestruturas físicas e sociais dá origem a uma crescente indústria privada que opera no que costumava ser o setor público, conferindo a esses players uma importância (na) política cada vez crescente.

De posse da compreensão dos traços gerais do fenômeno denominado "financeirização", passa-se agora à segunda parte do artigo, que se debruça sobre as implicações das transformações até aqui vistas e suas implicações para o trabalho.

\section{Implicações para o trabalho}

Esta seção busca estabelecer uma relação entre a flexibilidade na "nova" forma de acumulação do capital, isto é, predominantemente na forma financeira, e a própria flexibilidade e demais consequências para o trabalho, especialmente do ponto de vista conceitual (mais abstrato). 
Bauman (2001, p.188) observa que, de um ponto de vista espacial, a liberdade de movimentos do capital ensejou uma ruptura (embora não completa) de sua dependência em relação ao trabalho na medida em que "a reprodução e o crescimento do capital, dos lucros e dos dividendos e a satisfação dos acionistas tornaram-se independentes da duração de qualquer comprometimento local com o trabalho". A "modernidade sólida" ou "capitalismo pesado" (equivalente à era do fordismo) tinha como característica o engajamento e dependência mútua entre capital e trabalho em um mesmo habitat comum, isto é, um endereço fixo, que era a fábrica. Na "modernidade líquida" ou "capitalismo leve", isto é, com o advento da mundialização financeira, a flexibilidade reivindica trabalhos via contratos de curto prazo ou mesmo ausência de contratos. O capital fluido apresenta um poder de barganha sem precedentes face às instituições locais. Estabelece, "paradoxalmente", sua liberdade de saída sem embaraços como condição de sua permanência, o que deságua na flexibilização do mercado de trabalho e abolição de restrições legais ao seu livre movimento.

Essa flexibilidade apresenta vários matizes. Dal Rosso (2017) busca categorizá-las da seguinte maneira: há basicamente dois tipos de flexibilidade: externa (relacionada propriamente ao vínculo do trabalhador com a empresa) e interna (que diz respeito à gestão do trabalhador). Cada um desses tipos pode ser, por sua vez, de ordem quantitativa (em relação ao número de trabalhadores ou horas de trabalho) ou qualitativa (considerando o tipo de contrato e a função do trabalhador).

Assim, flexibilidade externa quantitativa diz respeito ao número de trabalhadores envolvidos, que varia conforme a necessidade da empresa; flexibilidade externa qualitativa considera a substituição do tradicional contrato por tempo indeterminado por formas atípicas, de fácil cancelamento, como contrato por tempo determinado (temporário), parcial ou a própria terceirização.

Já a flexibilidade interna quantitativa está relacionada às variações nos horários de trabalho (extensão da jornada ou diminuição) de acordo com os interesses da empresa, por exemplo, horas extras, banco de horas. Por fim, temos a flexibilidade interna qualitativa, também chamada de flexibilidade funcional, onde o empregado é compelido a ser polivalente, isto é, acumular tarefas e habilidades de várias funções.

Há ainda a flexibilidade salarial: na impossibilidade de redução da remuneração, a empresa altera qualitativamente o salário lançando mão de instrumentos como bônus, abonos e metas. É recorrente a tentativa dos bancos, veementemente rechaçada pelas instituições sindicais, de transformar parte do reajuste em abono, por exemplo. Há também a flexibilidade de lugar: ganha força a ideia de o funcionário desempenhar o trabalho fora da empresa - home office, o que leva à invasão de horários de não-trabalho.

Vale salientar o papel institucional do Estado na implementação de formas flexíveis de trabalho. Não existia regulamentação específica para o trabalho em tempo parcial e por tempo determinado, mas ao dar-lhes vida por ação legislativa, os governos realizaram uma verdadeira desregulamentação legislada (DAL ROSSO, 2017). Esse argumento é análogo ao de Helleiner (1994), para o contexto da "desregulação" financeira.

Bryan, Martin e Rafferty (2009) argumentam que a financeirização muda a maneira de como se interpreta as categorias trabalho e capital. As contradições do trabalho como capital não são algo novo. Enquanto que, no contexto da Lei de Say, o trabalho é um custo, para Keynes, é fonte de demanda. Logo, um aumento nos salários se traduz como algo positivo para o capital, enquanto incremento da demanda, e negativo, enquanto elevação dos custos. Trata-se de um dilema cuja solução teórica aparece de forma extrínseca no espaço - por meio do aumento das exportações líquidas, isto é, poupança externa - e no tempo - via crédito ao consumidor ou déficit público, ou seja, um desequilíbrio intertemporal nas finanças. Assim, o trabalho é e não capital ao mesmo tempo.

Na tradição marxista (MARX, 2011), o trabalho pode ser visto como duas formas de capital:

1. Capital mercadoria - força de trabalho capaz de gerar bens tangíveis e intangíveis, que é trocada por salários;

2. Capital variável - o trabalho enquanto substância do valor, isto é, o elemento que reproduz o equivalente ao seu próprio valor e também produz um excesso, o mais-valor, cuja repartição (apropriação) entre os diferentes tipos de lucros (lucro do empreendimento, lucro de circulação, juros) vai depender da competição intra capitalista. É variável, portanto, porque no processo de produção sofre alteração de valor, diversamente do capital constante (máquinas e instrumentos).

A financeirização, nos seus diversos aspectos, muda a compreensão do trabalho como capital mercadoria e como capital variável (BRYAN, MARTIN, RAFFERTY, 2009). No primeiro aspecto (capital mercadoria), esses autores argumentam que a financeirização se processa como a incursão direta do cálculo capitalista no interior das famílias. O esquema a seguir ilustra este fato. O valor da força de trabalho é definido de forma análoga ao valor das outras mercadorias, isto é, pelos custos socialmente necessários de sua reprodução (subsistência), que entram no esquema como uma espécie de "input", sendo o "output" a mercadoria "força de trabalho" (FIGURA 1). A finança, nessa etapa, desempenha um papel mormente instrumental. 
Figura 1 - Esquema de reprodução da mercadoria força de trabalho

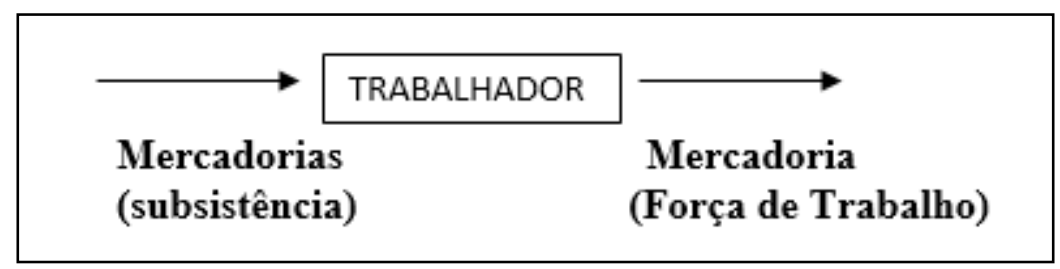

Fonte: elaboração própria

Com a financeirização, isto é, quando a finança assume a operação do processo de acumulação, a reprodução da força de trabalho começa não com mercadorias, mas com crédito (FIGURA 2). Ocorre a transformação das relações monetárias em relações de mercadorias, isto é, uma comodificação que obscurece a distinção entre dinheiro e capital. O crédito é usado para comprar as mercadorias e serviços de subsistência (insumos) para as famílias. Uma parte dos salários (s) pagos à força de trabalho acumula-se na forma de pagamentos de juros (j) sobre o capital monetário previamente disponibilizado para as famílias. Percebe-se que esse compromisso com o pagamento de juros ocorre independentemente do recebimento de salários. Dessa forma, o padrão de vida dos trabalhadores é determinado pela extensão do salário residual (s-j). Sob a perspectiva do capital, esse salário residual (salário pós-juros, s-j) aparece como excedente do trabalho, sendo alvo de um ataque competitivo por parte dos capitalistas (BRYAN, MARTIN, RAFFERTY, 2009).

Figura 2 - Esquema de reprodução da mercadoria força de trabalho com financeirização

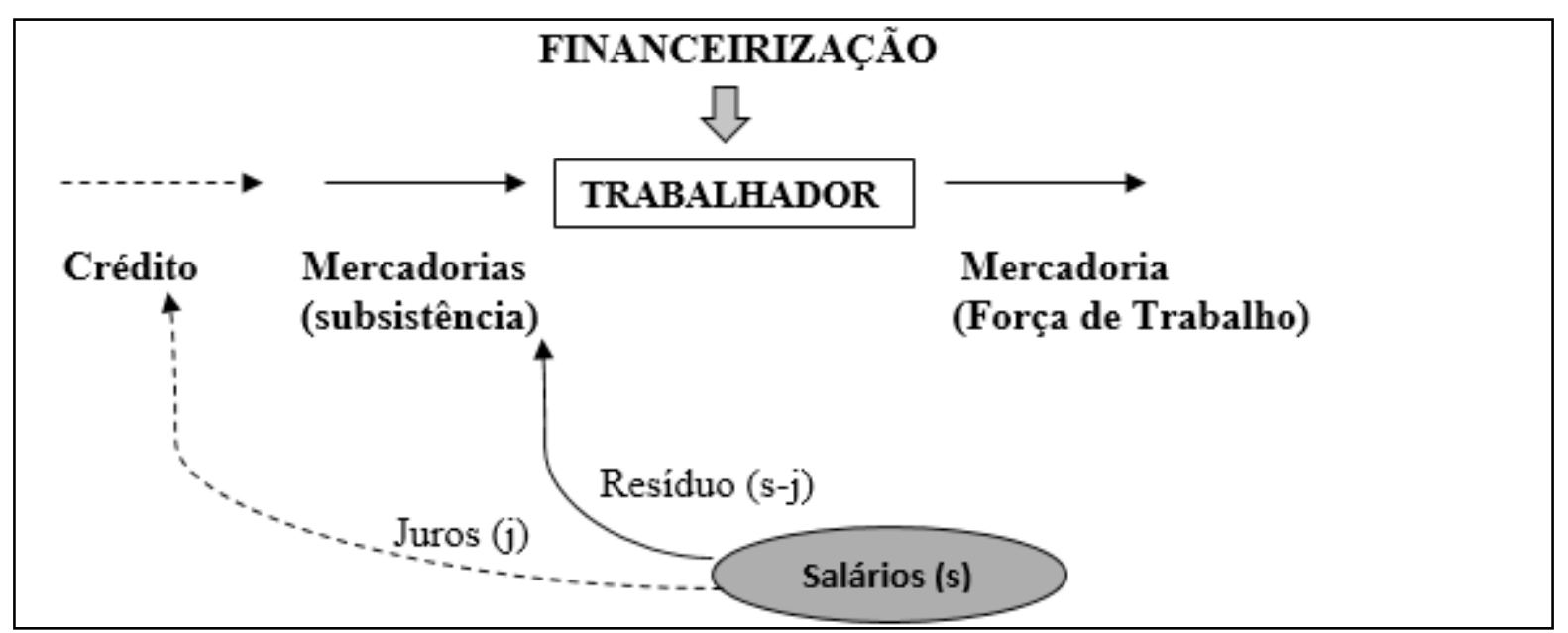

Fonte: elaboração própria

Com a transformação dos direitos em mercadorias, isto é, em produtos financeiros, surge o apelo e a necessidade do conhecimento financeiro para alocar os recursos entre saúde, educação e aposentadoria (sobretudo a partir da proliferação dos sistemas de aposentadoria do tipo "contribuição definida"). Isto acaba desaguando em uma exposição ao risco e transferência da responsabilidade ao próprio trabalhador que antes recaía sobre o Estado. "O corolário (...) é que o trabalhador (supostamente) letrado financeiramente pode, moral e juridicamente, assumir a responsabilidade pelo seu próprio sucesso financeiro e fracasso" (BRYAN, MARTIN, RAFFERTY, 2009, p.5). Essa interpretação, no entanto, não é incontroversa mesmo dentro do campo (supostamente) "progressista".

Standing (2015) vê no próprio processo de financeirização uma saída para os problemas que ele próprio engendra. Analisando o precariado, qual seja uma classe em formação caracterizada pela empregabilidade em condições de insegurança e instabilidade, o autor vislumbra que a solução passa sobre a posse do saber sobre finança:

A luta pelo conhecimento financeiro consiste em permitir que o precariado seja eficiente no tratamento de questões financeiras. A estrutura fiscal da moderna sociedade de mercado é imensamente complexa, permitindo que aqueles com acesso a especialistas em impostos ganhem muito mais dinheiro, enquanto os "pequenos" pagam mais impostos do que deveriam. O direito ao conhecimento financeiro e aos serviços financeiros públicos é mais importante do que muitos presumem. O precariado deve em breve mobilizar-se em torno de demandas por um direito universal de receber conhecimento financeiro. No contexto do endividamento pessoal crônico, devido a "tubarões agiotas " e dívidas estudantis que se estendem para o futuro, isso não é mais uma questão menor (STANDING, 2015, p.14). 
Bryan, Martin e Rafferty (2009), no entanto, identificam impactos da financeirização em três dimensões:

1. A própria reprodução da força de trabalho converte-se em mais uma maneira de extração do mais-valor na forma juros, analogamente ao que acontece quando o excedente é distribuído entre as diferentes funções do capital: lucro empresarial, renda, juros (novamente) etc.

2. Como parte da renda do trabalho vira pagamento de juros, então a queda nos salários se manifesta não apenas como queda no poder de compra, mas também como incremento de risco e custo ao credor. O risco de default sinaliza a ineficácia da renda do trabalho funcionar como capital.

3. O trabalho como capital tem sua existência determinada pela taxa de juros.

No que diz respeito o impacto da financeirização no trabalho enquanto capital variável, Bryan, Martin e Rafferty (2009) enfatizam o papel da securitização e dos derivativos, instrumentos financeiros que constituem o cerne do processo de financeirização. Para os autores, "a securitização envolve enquadrar um ativo ou uma coleção de ativos em termos de seus fluxos de receita esperados e vender direitos ao fluxo de renda, mas sem transferência necessária de propriedade do próprio ativo subjacente" (BRYAN, MARTIN, RAFFERTY, 2009, p.8). Todo ativo que enseja um fluxo de renda pode ser agrupado e transacionado no mercado, isto é, securitizado. Assim, ativos que isoladamente teriam um mercado muito restrito - por exemplo, por conta do elevado risco de default ou questões relacionadas à regulação - ao serem reunidos a outros ativos cujo mercado é mais amplo, tornam-se um novo produto, com acesso a outros mercados. Assim, a securitização não deixa de ser uma forma de "burlar" o sistema: ativos que isoladamente não transacionariam em determinado mercado, quando travestidos em um novo produto, passam a acessar esse mercado, amiúde à revelia dos próprios participantes, que sequer têm noção do conteúdo real daquilo que estão adquirindo.

Já os derivativos não envolvem um direito a um fluxo de renda, são instrumentos cuja variação de preço referenciam a performance de outros instrumentos financeiros, a título de hedge. A securitização e os derivativos permitiram separar distintos aspectos do capital em commodities negociáveis em distintos mercados, ensejando novas pressões competitivas. Ativos considerados como tendo desempenho inferior em referência às normas de mercado têm seus valores imediatamente reduzidos. O próprio trabalho passa a ser também tratado como uma forma de capital, um risco a ser decomposto, precificado, protegido e gerenciado, compelido a entregar taxas competitivas de mais-valor (BRYAN, MARTIN, RAFFERTY, 2009). A fluidez do capital que vem com a securitização e os derivativos traz uma competitividade intensificada para a valorização do capital, com impacto (pressão) no labor:

Por meio de uma avaliação do desempenho do capital, há implicações diretas para o trabalho como capital variável. A necessidade de atender a taxas competitivas de retorno em cada faceta da acumulação traz a mão-de-obra imediatamente para o cálculo como parte do desempenho do capital. A remuneração da mão de obra está sujeita à avaliação contínua em tempo real nos mercados de derivativos e de valores mobiliários; ela não é avaliada apenas em dados anuais ou trimestrais sobre a rentabilidade agregada da empresa. A expectativa do mercado de preços de ativos é ao mesmo tempo uma expectativa da produtividade da mão de obra em relação ao seu salário - sua taxa de mais-valor (BRYAN, MARTIN, RAFFERTY, 2009, p.10-11).

\section{E adiciona:}

Onde quer que os mercados financeiros - sejam eles mercados de crédito, segurança ou derivativos - imponham normas à acumulação, uma intensificação de mão-de-obra impulsionada pela competitividade certamente se seguirá. Enquanto a relação salarial envolve um pagamento retrospectivo para trabalhar pelo mais-valor passado, o crédito ao consumidor, como relação do trabalho com o capital sobre o futuro, implica a diluição do mais-valor antes da participação na "produção" e assim intensifica o compromisso do trabalho com o próprio sistema de produção (BRYAN, MARTIN, RAFFERTY, 2009, p.14).

A financeirização engendra uma contradição nas relações de classe, que é um ponto central do próprio neoliberalismo: a ideia de que todos os indivíduos são acumuladores, cujo sucesso individual é "inteiramente contingente ao nosso próprio desempenho, não apenas em acumular "capital humano", mas também em avaliar e gerenciamento de oportunidades e riscos” (BRYAN, MARTIN, RAFFERTY, 2009, p.11).

De acordo com Trenkle (2015), houve uma mudança qualitativa na relação entre capital e trabalho com o fim do período fordista (welfare-state). Até a década de 70, a forma sistemática pela qual o capital se valorizava, em maior medida, era através da sua relação direta com a força de trabalho. A partir das transformações tecnológicas da terceira revolução industrial e suas implicações, como a automação, a principal força produtiva passou a ser a aplicação do conhecimento na produção, tornando "redundante" boa parte da força de trabalho, o que acabou por 
conferir ao capital uma vantagem em relação ao trabalho assalariado. Sucede que, como a valorização de capital é necessariamente baseada na exploração da força de trabalho na produção de mercadorias em grande escala, esta mudança qualitativa trouxe também o início de uma crise fundamental. O que ele chama de "era do capital fictício" pode ser entendido como uma faceta fundamental do processo de financeirização. Trata-se de uma época em que

a acumulação de capital já não é significativamente baseada na exploração do trabalho na produção de mercadorias como carros, hambúrgueres e smartphones, mas sobre a emissão maciça de títulos de propriedade, como ações, obrigações e derivativos financeiros, que representam reivindicações de valor futuro. Como resultado, o próprio capital fictício tornou-se o mecanismo de acumulação de capital, enquanto a produção de matérias-primas foi reduzida a uma variável dependente (TRENKLE, 2015, p.6, grifo nosso).

Na visão de Trenkle, a crise fundamental está relacionada ao fato de que é um processo de acumulação de capital, mas sem valorização real de capital. Há uma diferença temporal. A financeirização, diversamente do período fordista, baseia-se de forma mais direta e imediata não na exploração da força de trabalho no processo de produção de valor presente, mas sim na expectativa de lucros futuros, que devem, em última instância, advir de exploração adicional de trabalho.

No entanto, é impossível resgatar todas as reinvindicações de valor futuro que surgem, dessa forma, é necessário que estas reinvindicações sejam sistematicamente renovadas e, a depender do mecanismo, outras sejam criadas, levando a riqueza abstrata a patamares sucessivamente mais elevados. Nesse sentido, o gap entre a riqueza material e a fictícia decorre de uma necessidade objetiva do capital, pois apenas assim a acumulação pode continuar (TRENKLE, 2015). O deslocamento no processo de acumulação, isto é, a deposição da produção de bens materiais na forma de mercadoria como principal forma de aumentar o capital, afeta diretamente o trabalho - em desfavor aos trabalhadores - pois

Sua mercadoria [a força de trabalho] não é mais a mercadoria de base da acumulação de capital. Isso nos deixa com um desequilíbrio estrutural. Para a grande maioria da população do mundo, a mediação social pelo trabalho permanece como meio crucial de como eles devem vender sua força de trabalho ou os produtos de seu trabalho como uma mercadoria aqui e agora, a fim de poder participar na riqueza da sociedade - o que quer dizer, a fim de comprar os artigos de consumo que eles precisam. O capital também continua a basear-se na mediação social pelo trabalho, porque ele não tem como abandonar o mundo da produção de mercadorias. No entanto, na medida em que o capital se acumula por meio de antecipação de produção de valor futuro (ou seja, ele usa os resultados do potencial de trabalho futuro com antecedência), ela se liberta da dependência de exploração do trabalho atual e dos vendedores de força de trabalho (TRENKLE, 2015, p. 8-9).

Neste contexto, de ponto de vista da acumulação do capital, há uma redefinição do papel da produção. Esta não mais lhe serve, predominantemente, como meio direto, mas sim como base material que sanciona e sustenta as expectativas futuras dos mercados financeiros. É nesse sentido que a acumulação capitalista no contexto da financeirização não prescinde da produção. Mesmo que, no presente, ainda dependa apenas o suficiente para manter a plausibilidade das promessas de realização. Trenkle (2015) aponta duas importantes implicações decorrentes desta condição da produção de mera base material para referenciar as expectativas futuras:

1. O capital tende a se tornar cada vez mais indiferente aos conteúdos, às condições e às consequências da produção;

2. As condições de venda da mercadoria força de trabalho deterioram-se. Isto significa, neste contexto, que o capital assume uma posição cada vez mais confortável no seu propósito de acumulação na forma fictícia e também na forma tradicional.

Do ponto de vista mais concreto, portanto, isto se traduz em uma precarização sistemática das condições de trabalho, reversão de direitos conquistados, enfraquecimento dos sindicatos, etc.

\section{Considerações finais}

A financeirização envolve a predominância dos mercados e demais instituições financeiras como a forma par excellence de definição, gestão e realização da riqueza no capitalismo contemporâneo. Isso significa dizer que se trata de um fenômeno necessariamente multifacetado cuja análise pode ser feita a partir de diferentes ângulos. A depender do local e do contexto, alguns desses ângulos assumem maior ou menor relevância. Portanto, do ponto de vista concreto, a financeirização pode, a um só tempo, manifestar-se de formas diversas em diferentes partes do globo, seja do ponto de vista da mudança na governança interna da firma, seja no que diz respeito ao papel do Estado e sua interação com o setor privado. 
O processo de financeirização da economia foi possível a partir de um processo subjacente de flexibilização, que se consubstanciou em uma nova forma de regulação bem como no advento de novos instrumentos financeiros, notadamente securitização e derivativos. Isto ensejou um aumento inaudito no grau de liberdade, no volume e na complexidade do movimento de capitais, trazendo a competição capitalista a outro patamar. Isto acarretou mudanças tanto na forma de governança da firma quanto nas relações de trabalho.

A flexibilidade nos mercados financeiros e de crédito, embora não deva ser considerada causa única, teve parte significativa no advento da flexibilidade no trabalho. As distintas considerações aqui discutidas, embora sob perspectivas diferentes, apontam para uma deterioração das condições de trabalho a partir da competitividade intensificada para a valorização do capital na esfera financeira.

\section{Referências}

BAUMAN, Zygmunt. Modernidade líquida. Rio de Janeiro: Zahar, 2001.

BRAGA, José Carlos. Qual conceito de financeirização compreende o capitalismo contemporâneo. In: BARROSO, Aloísio; SOUZA, Renildo (Orgs.) A grande crise capitalista global 2007-2013: gênese, conexões e tendências. São Paulo: Anita Garibaldi: Fundação Maurício Grabois, 2013.

BRAGA, José Carlos; CINTRA, Marcos Antônio. Finanças dolarizadas e capital financeiro: exasperação sob comando americano. In: Fiori, José Luis (Org.). O poder americano. Petrópolis: Vozes, 2004. p. $253-307$.

BRYAN, Dick; MARTIN, Randy; RAFFERTY, Mike. Financialization and Marx: Giving Labor and Capital a Financial Makeover. Review of Radical Political Economics, Volume XX, No. X, Season XXXX, 2009.

CHESNAIS, François. O Capital portador de juros: acumulação, internacionalização, efeitos econômicos e políticos. In Chesnais, François. (org.). A Finança Mundializada. São Paulo: Boitempo Editorial, 2005

CRAMER, Maria; COATE, Jackson. A horrific injury. A heroic rescue effort. And a desperate plea: please don't call the ambulance, it costs too much, 2018. Disponível em: https://www0.bostonglobe.com/ metro/2018/07/02/woman-got-her-leg-caught-gap-orange-line-train-and-then-begged-for-ambulance-becausecost/q6gBPV8ujcfH0qLrQ6HjEJ/story.html?p1=Article_Related_Box_Article_More\&fbclid=IwAR0ZtJSiNPq7A25 Jw30jp5s8IljDpf-9A531hYRvmyJPZig0umvqi_-DIJQ Acesso em: 17 nov.2018

DAL ROSSO, Sadi. O ardil da flexibilidade: os trabalhadores e a teoria do valor. São Paulo: Boitempo, 2017.

EPSTEIN, Gerald. Financialization, rentier interests, and central bank policy. Amherst: University of Massachusetts, dec. 2001.

HELLEINER, Eric. States and the Reemergence of Global Finance: from Bretton Woods to the 1990s. New York: Cornell University Press, 1994.

KRIPPNER, Greta. The financialization of the American economy. Socio-Economic Review, v.3, n.2, p. 173-208, 2005.

LAZONICK, William. O’SULLIVAN, Mary. Maximizing shareholder value: a new ideology for corporate governance, Economy and Society, vol.29 n.1, 2000

LIPIETZ, Alain. La mondialisation de la crise generale du fordisme: 1967-1984. Les Temps Modernes, Paris, v. 8413, p. 695-796, oct.1984.

MARX, Karl. O capital: livro I. São Paulo: Boitempo, 2011.

PALLEY, Thomas. Financialization: what it is and why it matters. Annandale-On-Hudson: Levy Economics Institute, 2007. (Working paper, n. 525).

POZZI, Sandro. Financiamentos afundam os estudantes nos EUA: dívidas superam 5,9 trilhões de 
reais, 2018. Disponível em: https://brasil.elpais.com/brasil/2018/06/06/internacional/1528282199_859406. html?fbclid=IwAR0YUBWZHeDm3MelA7QGReAmuK77aJ4EKB0qoBWLIgNXBIaKd7cdg0BKDjI Acesso em: 25 nov.2018

STANDING, Guy. The Precariat and Class Struggle. RCCS Annual Review [Online], 2015.

STREECK, Wolfgang. How Will Capitalism End? Essays on a Failing System. New York: Verso, 2016.

THE EDITORIAL BOARD. This tweet captures the state of health care in america today, 2 jul. 2018. Disponível em: https://www.nytimes.com/2018/07/02/opinion/boston-subway-accident-health-care.

html?fbclid=IwAR1faWl7iX770uTCj3V6PTch7P6_azBg7 AMbm2gmGNnocybX-R_bWZ-UFuo Acesso em: 18 out. 2018

TRENCKLE, Norbert. Labour in the era of fictitious capital, 2015. Disponível em: http://www.palim-psao. fr/2015/08/labour-in-the-era-of-fictitious-capital-by-norberttrenkle.html. Acesso em: 25 nov. 2018.

VAN DER ZWAN, Natascha. Making Sense of Financialization. Socio-Economic Review, Vol. 12, No. 1, p. 99-129, 2014. 